\title{
Correspondence
}

\section{Two years after introduction, trainees remain unconvinced about WPBAs and ARCPs}

Several surveys conducted in the first year after the introduction of workplace-based assessments (WPBAs) in 2007 show poor satisfaction with this process. ${ }^{1-3}$ Our survey of trainees conducted in 2009 shows ongoing concerns with WPBAs 2 years on.

Of the 146 trainees who participated in our electronic survey, $40 \%$ did not feel that WPBAs had led to improvements in patient care, with $31 \%$ unsure. Furthermore, $68 \%$ considered that WPBAs did not help/were only slightly helpful to them in passing their MRCPsych examination. Of those who were in psychiatric training before WPBAs were introduced (67\%),

$70 \%$ reported no improvement in their training!

However, $88 \%$ of trainees rated their satisfaction reasonably high on the quality of feedback they received (at 3 or above on a 5-point Likert scale). Norcini \& Burch ${ }^{4}$ stress that formative assessment and feedback are a powerful means for changing behaviour in trainees, and that feedback can have a major influence on learning. On the face of it, our results seem strange, as trainees do not seem to acknowledge or recognise the helpfulness of this new method of assessment on their training experience.

The online filing of WPBA has improved greatly in 2008 . The faulty Healthcare Assessment and Training computer system (originally in use to record WPBAs) can no longer be blamed for trainee dissatisfaction, as in earlier surveys. ${ }^{1}$ Our concurrent survey of 50 consultant trainers showed that they too had ongoing concerns about WPBAs. In particular, $80 \%$ of trainers felt that WPBAs had an impact on their work commitments. If trainers were more positive about these assessments, perhaps this would influence their trainees' perceptions.

Parallel with the WPBA, the annual review of competence progression (ARCP) panels have been introduced. The ARCP should be an important formative and summative part of training. In our survey, $44 \%$ of trainees and $20 \%$ of trainers felt ARCPs were not meaningful, with $30 \%$ of trainees and $42 \%$ of trainers not sure.

We acknowledge that the interpretation of our survey is limited by the reasonably low take-up among trainees and trainers. Yet our results concur with those of Menon et al's 2008 study $^{1}$ and therefore we feel that our survey cannot be simply ignored because of the low response rate.

We agree with Menon et al that these new tools for evaluation and feedback should not be abandoned. However, further training of both trainers and trainees is needed to achieve better usage and a clearer understanding of the constructive role they should play in training, particularly with respect to the role of feedback.

Employers need to recognise that consultant psychiatrists require more time in their job plans for training future psychiatrists.

1 Menon S, Winston M, Sullivan G. Workplace-based assessment: survey of psychiatric trainees in Wales. Psychiatr Bull 2009; 33: 468-74.
2 Babu KS, Htike MM, Cleak VE. Workplace-based assessments in Wessex: the first 6 months. Psychiatr Bull 2009; 33: 474-8.

3 Pathan T, Salter M. Attitude to workplace-based assessment (letter). Psychiatr Bull 2008; 32: 359.

4 Norcini J, Burch V. Workplace-based assessment as an educational tool: AMEE Guide No31. Med Teach 2007; 29: 855-71.

Venkata B. Kolli is ST4, Suffolk Mental Health Partnership NHS Trust, email: venkata.kolli@smhp.nhs.uk, Hugo deWaal is Associate Postgraduate Dean (Psychiatry), East of England Deanery, Somashekara Shivashankar is ST6 in psychiatry and Judy Rubinsztein is Coordinating Clinical Tutor at Suffolk Mental Health Partnership NHS Trust

doi: 10.1192/pb.34.3.114

\section{The future of workplace-based assessments for core trainees}

We were pleased to read the two surveys of trainees' and trainers' experiences of workplace-based assessments (WPBAs) $)^{1,2}$ and the accompanying commentary ${ }^{3}$ in which Femi Oyebode neatly put his finger on some of the difficulties and challenges that have accompanied the College's adoption of these training tools. Inadequate training of hard-pressed trainers, lack of clarity concerning the relative importance of formative and summative functions, and the increasing bureaucratisation involved in the collection of portfolio evidence have all obscured the potential usefulness of the assessments. We thought that it would be useful for us to report how the College is planning to help trainees and trainers with the WPBAs for core training in the light of our own concerns and those reflected in the journal.

Delivery of anything more than the most superficial training in WPBAs to all clinical and educational supervisors has proved challenging. Consultant trainers are overwhelmingly conscientious about their responsibilities in delivering supervision and completing assessments but have found it hard to access WPBA trainer training. We have asked each of the Faculty Education and Curriculum Committees to produce a series of new standardised WPBAs, each one based on an important curriculum competency, and to provide a singlepage trainer's guide to that specific assessment that will tell the trainer exactly what should be covered and what is expected from their trainee to complete the assessment satisfactorily. These 'set' assessments, together with the relevant trainer's guides, will appear in a few months on Assessments Online (https://training.rcpsych.ac.uk) when trainers and trainees log on to complete an assessment. Our hope is that this will provide in-service training for assessors as well as a series of WPBAs whose content is consistently high and focused upon acquisition of the most important curriculum competencies. The Chief Examiner has offered to provide Clinical Assessment of Skills and Competences (CASC) examiner training to interested trainers - even if they are not necessarily intending to examine - to help them to understand how their trainees will be expected to perform by the end of core training and to strengthen the robustness of their own assessments during supervision. We will be 